\title{
Impact of an Educational Strategy on Patients with Overweight and Obesity
}

\author{
Jiménez Herrera Karina ${ }^{1}$, Chacón Valladares Paula ${ }^{1}$, Estrada Andrade María Elena ${ }^{2}$, Gómez Alonso \\ Carlos $^{3}$ and Muñoz Cortes Gerardo ${ }^{1 *}$
}

${ }^{1}$ Department of Education and Research, Instituto Mexicano del Seguro Social, Michoacán, México

${ }^{2}$ Department of Education, Primitivo y Nacional Colegio de San Nicolas, Universidad Michoacana de San Nicolás de Hidalgo, Michoacán, México

${ }^{3}$ Biomedical Research Center of Michoacán, Instituto Mexicano del Seguro Social, Michoacán, México

\begin{abstract}
Introduction: Overweight and obesity are a public health problem, which continues to increase in recent decades and is associated with chronic diseases. NutrIMSS is a strategy of the Mexican Institute of Social Security (IMSS) that promotes a healthy lifestyle and provides education to patients on proper nutrition, water consumption and practice of physical activity.

Objective: To evaluate the impact of an educational strategy on clinical and biochemical indicators in overweight or obesity patients.

Materials and methods: Descriptive, longitudinal and prospective study in patients of the Family Medicine Unit No. 80 from Morelia Michoacán, Mexico, with diagnosis of overweight or obesity, through an educational strategy based on NutrIMSS strategy, that included: Three educational sessions, nutritional care and inclusion to the social security center for regular physical activity. Anthropometric and biochemical measurements were taken at month 0 and at month 6 , March-August 2017, participants who did not fulfill $80 \%$ of the NutrIMSS strategy assistance were excluded. The data are presented whit mean \pm standard deviation, t-student related samples, statistical significance: $p<0.05$.

Results: 30 patients, $67.7 \%$ women. Pre-intervention and post-intervention anthropometric parameters: Weight $(\mathrm{Kg})$ : $80.82 \pm 12.67,78.86 \pm 12.36(0.002)$, BMI (kg/m²): $30.40 \pm 3.93,29.59 \pm 3.83$ (0.001), abdominal waist (cm): $97.38 \pm 12.28$, $96.41 \pm 12.04(0.009)$, systolic blood pressure $(\mathrm{mmHg}): 117 \pm 6.90,114 \pm 7.24(0.001)$, diastolic blood pressure $(\mathrm{mmHg})$ : $76 \pm 5.57,74.70 \pm 5.71$ (0.096), glucose (mg/dl): $94.20 \pm 12.35,89.70 \pm 10.56(0.009)$, total cholesterol (mg/dl): $164.47 \pm$ $29.01,152.40 \pm 30.80$ (0.012), High density lipoprotein (mg/dl): $52 \pm 13.07,44.20 \pm 11$ (0.001), Low density lipoproteins $(\mathrm{mg} / \mathrm{dl}): 84.90 \pm 19.62,87.70 \pm 19.46(0.321)$ and triglycerides $(\mathrm{mg} / \mathrm{dl}): 127.70 \pm 41.58,119.20 \pm 36(0.215)$
\end{abstract}

Conclusion: There is a positive impact of the educational strategy on clinical/biochemical values in overweight and obese patients.

\section{Keywords}

Overweight, Obesity, Educational strategy

\section{Introduction}

Obesityis a systemic, chronic, progressive and multifactorial disease, characterized by excessive accumulation of fat [1], accompanied by metabolic alterations, and predispose to health alterations [2]. It is a pathology in which factors of risk and comorbidities must be looked for associated, mainly Diabetes Mellitus (DM) and cardiovascular disease. In the world 1.7 billion suffer from obesity [1], projecting 1.12 billion of patients with obesity in 2030 [3], and producing $60 \%$ of all deaths [4]. In Mexico there is a prevalence of overweight and obesity of $72.5 \%$ [5].

The main causes of overweight and obesity include: High caloric intake, sedentary lifestyle, and genetic predisposition [6], added to factors that increase the problem, such as lack

*Corresponding author: Gerardo Muñoz Cortes, Department of Education and Research, Family Medicine Unit No. 80, Instituto Mexicano del Seguro Social, 1200 Madero Avenue, Centro, CP. 58000, Morelia, Michoacán, México, Tel: 4433477907

Accepted: November 19, 2018

Published online: November 21, 2018

Citation: Karina JH, Paula CV, Elena EAM, et al. (2018) Impact of an Educational Strategy on Patients with Overweight and Obesity. Arch Fam Med Gen Pract 3(1):60-65

Copyright: (c) 2018 Karina JH, et al. This is an open-access article distributed under the terms of the Creative Commons Attribution License, which permits unrestricted use, distribution, and reproduction in any medium, provided the original author and source are credited. 
of access to food and environments that don't promote physical activity [7]. The treatment must include a healthy diet and exercise, together with conduct modification, to comprehend a long-term attachment [8], therefore, it is important to implement educational strategies that modify these conducts.

Obesity is characterized by increased risk of prehypertension (systolic blood pressure 120-139 $\mathrm{mmHg}$, diastolic blood pressure $80-89 \mathrm{mmHg}$ ) [9], prediabetes (fasting blood glucose level $100-125 \mathrm{mg} / \mathrm{dL}$ ) [10], and dyslipidemia (total cholesterol $\geq 200 \mathrm{mg} / \mathrm{dL}$, Low Density lipoproteins $\geq 160 \mathrm{mg} /$ $\mathrm{dL}$, High Density lipoproteins $<40 \mathrm{mg} / \mathrm{dL}$ and triglycerides $\geq$ $150 \mathrm{mg} / \mathrm{dL})[11,12]$.

Diagnosis of overweight and obesity is made by calculating the body mass index (BMI) and is classified as: Overweight 25-29.99 kg/m²; obesity grade I $30-34.99 \mathrm{~kg} / \mathrm{m}^{2}$; obesity grade II $35-39.99 \mathrm{~kg} / \mathrm{m}^{2}$; obesity grade III $>40 \mathrm{~kg} / \mathrm{m}^{2}$ [13], in addition, central obesity can be measured when the waist circumference in women $>80 \mathrm{~cm}$ and in men $>90 \mathrm{~cm}[14,15]$.

The Organization for Economic Cooperation and Development (OECD), overweight reaches an expenditure of $25 \%$ in health service [16].

NutrIMSS is an educational intervention created by the Instituto Mexicano del Seguro Social (IMSS), in 2015, with nutritional care in first level of care, aimed at the treatment of overweight and obesity; prepare to the patients for decision making in the form of preparation and choice of food, portions and schedules, associated with a physical activity [17], and combining a reflection of healthy lifestyles [18].

Current programs include strategies that modify lifestyle, confirming that they are capable of leading to long-term weight loss [19], however, it has not been studied in Family Medicine Unit No. 80 (UMF 80), which it is the impact that this strategy has, based on the NutrIMSS strategy. Therefore, the objective of this study was to evaluate the impact of an educational strategy on clinical and biochemical indicators in overweight and obese patients.

\section{Material and Methods}

Descriptive, longitudinal prospective study in patients of the Family medicine Unit No. 80 of the Mexican Social Security Institute (IMSS), Morelia, Michoacán, Mexico. The selection criteria were overweight or obese patients, aged 20 to 59 years, who could exercise; No pregnant patients, with comorbidities (diabetes mellitus, high blood pressure) or metformin treatment were included; Participants who did not attend $80 \%$ of educational sessions, nutrition appointments or physical activity were excluded. Convenience sampling was performed and 40 patients were selected from March to August 2017.

The educational strategy in patients with overweight and obesity included: 3 weekly educational sessions based on the educational program of the NutrIMSS strategy, monthly nutritional guidance for six months and physical education activities (three times a week) for 6 months.

Each educational session lasted 45 minutes and included an initial dynamic of integration (10 minutes), the participative educational strategy ( 25 minutes) and a closing with conclusions and clarification of doubts (10 minutes), which was implemented by a resident of family medicine supported by a master in education.

Session 1, "knowing my nutritional status" had as objective that the patient himself identify his current weight after the interpretation of the Body Mass Index (BMI); who knew the causes and consequences of overweight and obesity: Diabetes, hypertension and dyslipidemias (didactic blind); as well as the advantages of an adequate weight (better physical condition and reduction of the risk to diseases) through a daily practice of physical activity (150 minutes per week).

Session 2, "learning with the plate of good eating"; had as objective that the patient learned about a healthy diet (canvas from the plate of good eating), contrasting it with a hypercaloric diet, and highlighting the Kilocalories (Kcal) of each meal; In addition, they were given the benefits of drinking clean water.

Session 3, "producing a healthy, rich and nutritious menu", whose objective was that the patient learns to make healthy menus through rations and portions, and classify the food groups into: vegetables, fruits, cereals and legumes, meat, milk, sugars and fats.

The patients who completed the educational sessions were given an appointment with the laboratory of clinical analysis (glucose, triglycerides, total cholesterol, HDL-cholesterol and LDL-cholesterol) and referred to the nutrition clinic. Initial nutritional counseling included an initial anthropometric measure (weight, height, body mass index, abdominal waist) and biochemistry (glucose, triglycerides, total cholesterol, HDL-cholesterol, LDL-cholesterol). In addition, a dietary assessment was conducted, through a 24-hour reminder, according to the Mexican equivalent food system, which is useful for designing custom feeding plans based on equivalent food (portion or ration), whose Food is similar to those of your group, both in quality and quantity, allowing to be interchangeable among themselves, and divided into the following groups: Cereals, vegetables, fruits, food of animal origin, milk and substitutes, legumes, fats, sugars and foods Energy-free. And based on the results of the participants, an individual and personalized nutritional plan was designed that included the subsequent supervision with the monthly appointments to verify the attachment to the feeding plan.

The physical activity of the participants was carried out in the social security center of Morelia, Michoacán, and included activities such as: Soccer, basketball, volleyball, swimming, yoga, among others, according to their physical capacity; these activities were carried out 3 times a week, with a duration of 50 minutes per day; This activity was supervised by a teacher in physical education, and was carried out for 6 months.

Numeric values are expressed as mean value $\pm S D$, $t$-student for related samples, statistical significance $(p)<$ 0.05 . For the analysis of data, the software package SPSS version $\mathbf{2 2 . 0}$ was used for analyses. This work was evaluated and approved by the local committee of ethics and health 


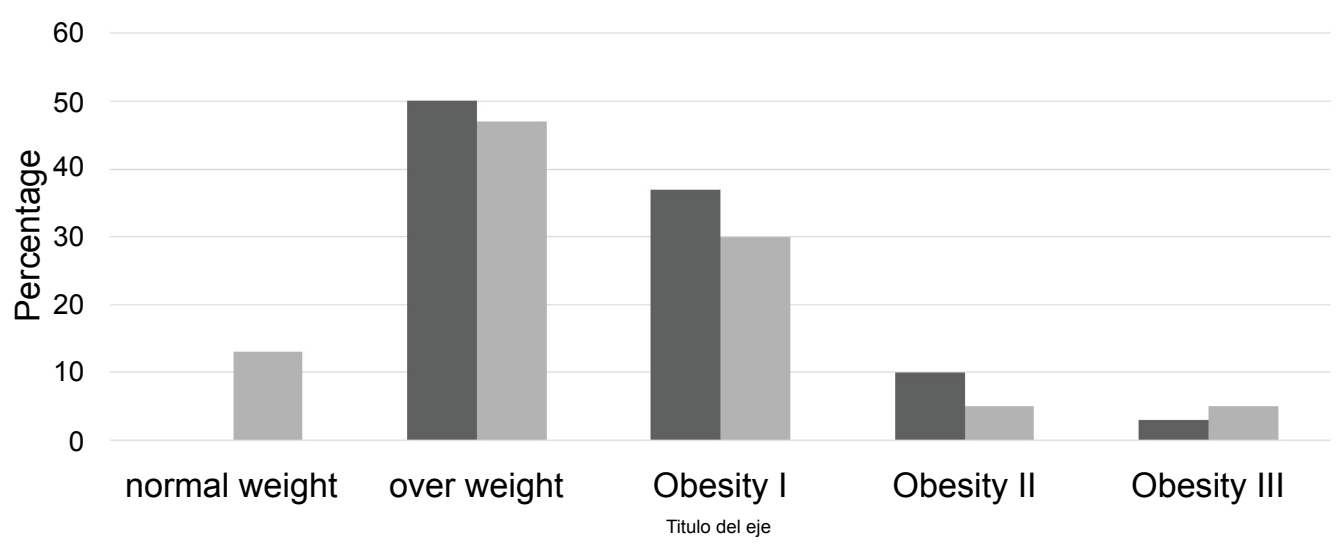

Pre-Intervention - Pos-Intervention

Figure 1: BMI pre and post-intervention of the educational strategy.

Table 1: Sociodemographic characteristics of the participants $(n=30)$.

\begin{tabular}{|l|l|l|}
\hline Variable & F & (\%) \\
\hline Civil Status & \multicolumn{2}{l|}{} \\
\hline Single & 12 & 40 \\
\hline Married & 18 & 60 \\
\hline Scholarship & & \\
\hline Primary & 1 & 3.3 \\
\hline High School & 7 & 23.3 \\
\hline Bachelor's Degree & 9 & 30 \\
\hline Postgraduate & 13 & 43.4 \\
\hline Occupation & & \\
\hline Housewife & 10 & 33.3 \\
\hline Student & 1 & 3.3 \\
\hline Worker & 5 & 16.7 \\
\hline Professional & 14 & 46.7 \\
\hline
\end{tabular}

F: Frequencies; \%: Percentage.

research of the IMSS, with registration number R-2016-16035. All the participants in the study were aware of the purpose of the research, collaborating freely by signing informed consent.

\section{Results}

30 of the 40 participants completed the educational strategy. The distribution by sex was: $33.3 \%$ male and $67.7 \%$ female, with an average age of $34 \pm 9$ years (range, 21 years to 58 years). The socio-demographic factors are shown in Table 1 ; note that there was a predominance of single patients, with postgraduate studies and professional occupation.

The eating habits of the participants were modified after the educational strategy. When making a comparison of means at the beginning and at the end of the educational intervention, there was a decrease in the intake of calories per day (1649 Kcal vs. $1444 \mathrm{Kcal}, \mathrm{p}<0.001)$.

In relation to physical activity, participants had changes related to the type and time of the activity. At the beginning, $23.4 \%$ exercised: $10 \%$ aerobic, $6.7 \%$ anaerobic and $6.7 \%$ mixed, while at 6 months, $100 \%$ exercised: $70 \%$ aerobic, $10 \%$ anaerobic and $20 \%$ mixed.
Table 2: Clinical indicators at the beginning and end of the educational strategy $(n=30)$.

\begin{tabular}{|l|l|l|l|}
\hline Indicator & $\begin{array}{l}\text { Pre-intervention } \\
\mathbf{X} \pm \text { SD }\end{array}$ & $\begin{array}{l}\text { Pos-intervention } \\
\mathbf{X} \pm \text { SD }\end{array}$ & $\mathbf{p}$ \\
\hline Weight $(\mathrm{Kg})$ & $80.82 \pm 12.67$ & $78.86 \pm 12.36$ & $0.002^{*}$ \\
\hline BMI $\left(\mathrm{Kg} / \mathrm{m}^{2}\right)$ & $30.40 \pm 3.93$ & $29.59 \pm 3.83$ & $<0.001^{*}$ \\
\hline Waist $(\mathrm{cm})$ & $97.38 \pm 12.28$ & $96.41 \pm 12.04$ & $0.009^{*}$ \\
\hline SBP $(\mathrm{mmHg})$ & $117 \pm 6.90$ & $114 \pm 7.24$ & $<0.001^{*}$ \\
\hline DBP $(\mathrm{mmHg})$ & $76 \pm 5.57$ & $74.70 \pm 5.71$ & 0.096 \\
\hline
\end{tabular}

BMI: Body Mass Index; SBP: Systolic Blood Pressure; DBP: Diastolic Blood Pressure; X: Mean; SD: Standard Deviation.

t student, "Statistically significant $(p<0.05)$.

The clinical parameters of the participants are shown in Table 2, note the changes at the beginning and end (six months post-intervention).

The impact of the educational strategy on the BMI of the participants is shown in Figure 1, note that at the beginning predominate overweight and obesity grade I (87\%) and there are no patients with normal weight, while at the end of the strategy, the percentages decrease in these categories and patient patients with normal weight are presented.

As far as the weight loss, 8 patients lost 1-4.9\%, 8 lost $5-9.9 \%$, no patient missed more than $10 \%$ and the remainder (14), was not lost in percentage (Figure 2).

The results of the impact of the educational strategy on the biochemical parameters can be seen in Table 3, note that the impact of the strategy was very significant in three biochemical variables (glucose, total cholesterol and high density lipoproteins).

\section{Discussion}

Overweight and obesity are a public health problem. Mexico and the United States, occupy the first places of global prevalence of obesity in the adult population at present, more than $70 \%$ of the adult population suffers [20].

The family doctor is a medical specialist who must implement health promotion actions to prevent overweight 


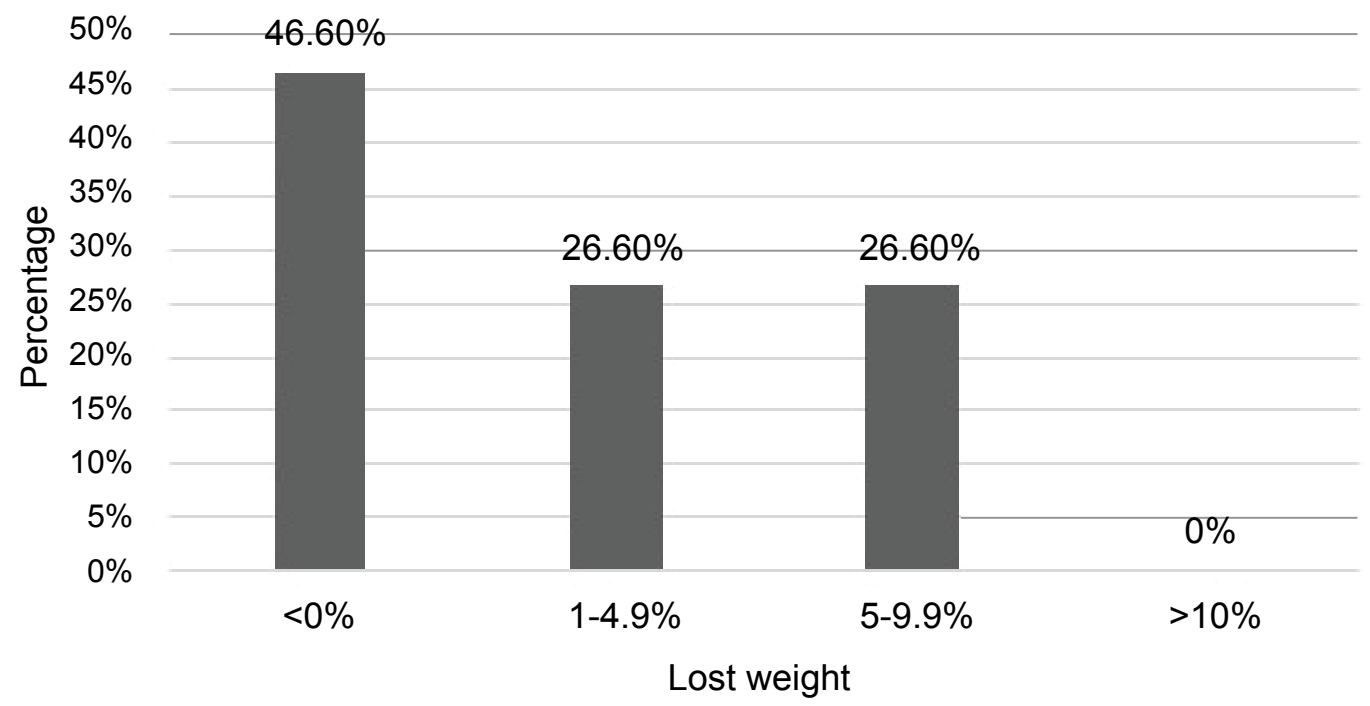

Figure 2: Weight loss in 6 months.

Table 3: Biochemical indicators at the beginning and end of the educational strategy $(n=30)$.

\begin{tabular}{|l|l|l|l|}
\hline Indicator & $\begin{array}{l}\text { Pre- } \\
\text { intervention } \\
\text { X } \pm \text { SD }\end{array}$ & $\begin{array}{l}\text { Pos- } \\
\text { intervention } \\
\text { X } \pm \text { SD }\end{array}$ & p \\
\hline Glucose $(\mathrm{mg} / \mathrm{dl})$ & $94.20 \pm 12.35$ & $89.70 \pm 10.56$ & $0.009^{*}$ \\
\hline Total Cholesterol $(\mathrm{mg} / \mathrm{dl})$ & $164.47 \pm 29.01$ & $152.40 \pm 30.80$ & $0.012^{*}$ \\
\hline c-HDL $(\mathrm{mg} / \mathrm{dl})$ & $52 \pm 13.07$ & $44.20 \pm 11$ & $<0.001^{*}$ \\
\hline c-LDL $(\mathrm{mg} / \mathrm{dl})$ & $84.90 \pm 19.62$ & $87.70 \pm 19.46$ & 0.321 \\
\hline Triglycerides $(\mathrm{mg} / \mathrm{dl})$ & $127.70 \pm 41.58$ & $119.20 \pm 36$ & 0.215 \\
\hline
\end{tabular}

c-HDL: High density cholesterol; c-LDL: Low density cholesterol; $\mathrm{X}$ : Mean; SD: Standard Deviation.

t student, ${ }^{*}$ Statistically significant figure $(p<0.05)$.

and obesity in families, however, when these diseases are already established, must provide education to patients that include changes in their healthy lifestyles.

In Mexico, different strategies have been developed, through a participatory strategy, to improve the learning process of patients. Well-structured educational strategies, which are offered individually or in groups, lead to appropriate learning and decision-making [21]. The strategy that was implemented in this study and that was based on the NutrIMSS strategy, promotes changes in food styles and increase in regular physical activity, was characterized by personalized nutritional accompaniment, since the nutritionist provided healthy dishes through menus tailored to the needs of patients. Therefore, the strategy that was implemented allowed a favorable impact on the clinical and biochemical parameters of the participants, as well as the work of Armenta, et al. [22], who carried out a strategy that included guidance on individual and group nutritional feeding, as well as physical activity recommendation, showed a decrease in weight $(-4.7 \mathrm{~kg}), \mathrm{BMI}\left(-1.70 \mathrm{~kg} / \mathrm{m}^{2}\right)$, systolic blood pressure and diastolic blood pressure, or like Luque and cols [23], who carried out an educational strategy with diet, appointments to nutrition every 21 days, prescription of exercise and health education with modification of habits, evidencing a decrease in BMI.

Analyzing the results and taking into account the factors demographic, singles dominated, excelling the professional level with $46.7 \%$, and a schooling greater or equal to bachelor; Agreeing with Moniño $M$, [24] who mentions the inequality existing in the population living at risk of poverty, which leads to a barrier to access to food and health services.

The impact of an educational strategy can be measured through a change in some variables, such as level of knowledge, satisfaction of participants, somatometric parameters, biochemical parameters, among others. Guzmán, et al. [25], showed that after an educational intervention of 6 months, in 16 patients with diabetes, with an average age of $54.2 \pm 14.5$ years, with $64 \%$ of the female participants, they can be reduced by 3 biochemical parameters: glucose (164.9 vs. $149.10 \mathrm{mg} / \mathrm{dl}, \mathrm{p}=0.127)$; total cholesterol (238.9 vs. 191.5 $\mathrm{mg} / \mathrm{dl}, \mathrm{p}=0.0025$ ) and triglycerides (283.2 vs. $181.2 \mathrm{mg} / \mathrm{dl}$, $p=0.014)$, a difference of the present study, which includes 30 participants, with a mean age of $34 \pm 9$ years , $67.7 \%$ women, a change was registered in 2 of these 3 biochemical parameters: glucose ( 94.20 vs. $89.70 \mathrm{mg} / \mathrm{dl}, \mathrm{p}=0.009)$, total cholesterol (164.47 vs. $152.40 \mathrm{mg} / \mathrm{dl}, \mathrm{p}=0.012$ ).

It is known that the strategies of treatment for obesity with losses of $5-10 \%$ of basal weight improve the parameters of the Cardiometabolic, Álamo y cols, [26] in a retrospective study studied the order of weight in a period of 2 years, in 177, 743 subjects; At 6 months they observed that $85 \%$ maintained stable weight $(<5 \%), 0 \%$ mild $(5-10 \%), 2 \%$ moderate loss $(10-15 \%)$ and $3 \%$ high loss (> 15\%); In comparison, in our study, it was observed that the total number of patients with educational strategy, $46.6 \%$ did not have weight loss, $26.6 \%$ maintained weight stable, $26.6 \%$ slight loss, and $0 \%$ lost moderate and high, without clutch, do not mention that strategy carried out.

It is very important to mention that educational strategies have a favorable impact when a transdisciplinary intervention is carried out, as shown by Arrebola, et al. [27], who 
conducted a study with diet, exercise, nutritional education and psychological support, led by a physician, nurse or dietitian, based on a reduction of moderate energy to the estimated daily intake at 6 months (2034 to $1751 \mathrm{kcal}, \mathrm{p}=$ 0.002); results very similar to those of this study in which a resident doctor of family medicine, a master in education, a nutritionist and a physical education teacher, achieving the reduction in the clinical parameters and also a change in the estimated capacity daily calorie intake (1649 to $1444 \mathrm{Kcal}, \mathrm{p}$ $<0.001)$.

Physical activity is an important factor to prevent obesity, however, on its own there is no such favorable impact that it is combined with healthy eating, as demonstrated by Álvarez, et al. [28] who conducted a study in 43 sedentary women in 12 weeks of intervention, with 3 different physical exercise programs: Interval program, program of physical exercise of overload and program of combined physical exercise, however, not significant changes in anthropometric variables, only in glucose, a difference of the educational strategy of this study, where the changes were reflected as much as the somatometric parameters as in the chemical ones, due to the combination of exercise and a healthy diet.

One of the strengths of our study was the accompaniment of the patients by the research team. Within the limitations of the study, the use of an analyzer within the work team and the monthly weight level of the ingested kilocalories have not been included, since they were only measured at month 0 and month 6 . In addition, physical activity was very different between each of the participants, in relation to time and intensity, which does not differ when showing the results. No evidence was obtained to justify the increase of LDL and disminucion of HDL, because the feeding depends on each patient. It is recommended in next studies to carry out a study with control group.

\section{Conclusion}

Overweight/obese patients who have a well-structured plan with close follow-up have a positive impact on clinical and biochemical parameters. The educational programs offered by the Instituto Mexicano del Seguro Social are available to people, with the aim of preventing chronic diseases and their complications and reducing costs at the institutional level.

\section{Acknowledgements}

To the Family Medicine Unit No. 80 of the Instituto Mexicano del Seguro Social and the Social Security Center in Morelia Michoacán, México.

\section{Conflict of Interest}

The authors declare no conflict of interest.

\section{References}

1. http://www.cenetec.salud.gob.mx/descargas/gpc/ CatalogoMaestro/046_GPC_ObesidadAdulto/IMSS_046_08_ EyR.pdf

2. h t t p://www.dof.gob.mx/not a d etalle. php?codigo $=5154226 \&$ fecha $=04 / 08 / 2010$
3. Barnes RD, Ivezaj V (2015) A systematic review of motivational interviewing for weight loss among adults in primary care. Obes Rev 16: 304-318.

4. González G, Ceballos R, Méndez B (2010) Obesidad más que un problema de sobrepeso. La ciencia y el Hombre 23.

5. http://transparencia.insp.mx/2017/auditorias-insp/12701_ Resultados_Encuesta_ENSANUT_MC2016.pdf

6. Stel J, Legler J (2015) The role of epigenetics in the latent effects of early life exposure to obesogenic endocrine disrupting chemicals. Endocrinology 156: 3466-3472.

7. García-García E, Llanta-Romero M, Kaufer-Horwitz M, et al. (2008) La obesidad y el síndrome metabólico como problema de salud pública. Scielo 50: 530-547.

8. Anton SJ, Marcuello FC, Truchuelo DM (2013) Endocrinología. In: Ruiz M Borja, Campos P Jame, Alonso García P Javier, Manual AMIR. Marban, Madrid España, 1-64.

9. Verdecchia P, Angeli F (2003) Séptimo informe del Joint National Committee para la prevención, detección, evaluación y tratamiento de la Hipertensión Arterial: el armamento está a punto. Rev Esp Cardiol 56: 843-847.

10. http://care.diabetesjournals.org/cgi/reprint/26/11/3160.pdf

11. Grundy SM, Becker D, Clark LT, et, al. (2002) Detection, evaluation, and treatment of high blood cholesterol in adults (Adult Treatment Panel III). Circulation 106: 3143-3421.

12. Norma Oficial Mexicana NOM-037-SSA2-2012, Para la prevención, tratamiento y control de las dislipidemias.

13. http://www.cenetec.salud.gob.mx/descargas/gpc/ CatalogoMaestro/718_GPC_Tratamiento_de_diabetes_ mellitus_tipo_2_/718GER.pdf

14. Barquera C, Campos N, Rojas R (2010) Obesidad en México: Epidemiología y políticas de salud para su control y prevención. Gac Med Méx 146: 397-407.

15. http://www.salud.gob.mx/unidades/cdi/nom/ compi/043ssa205.pdf

16. Estrategia Nacional para la Prevención y el Control del Sobrepeso, la Obesidad y la Diabetes (2013) Secretaria de Salud. 1: 1-115.

17. González J, Arriaga J, Borja V (2015) Guía Técnica de Educación Nutricional en Primer Nivel de Atención "Aprendiendo a comer bien". (1a. edn), Nutri-IMSS.

18. Fernández A, Cervantes T, Alvara P (2012) Estrategias de autocuidado en pacientes con diabetes mellitus tipo 2. Espec Médico-Quirúrgicas 17: 94-99.

19. Montesi L, El Ghoch M, Brodosi L, et al. (2016) Long-term weight loss maintenance for obesity: A multidisciplinary approach. Diabetes Metab Syndr Obes 26: 37-46.

20. Barrera-Cruz A, Rodríguez-González A, Molina-Ayala MA (2013) Escenario actual de la obesidad en México: Rev Med Inst Mex Seguro Soc 51: 292-299.

21. Díaz-Torres Y, García-Chávez E, Oseguera-Rodríguez JF, et al. (2015) Alcances de una estrategia educativa participativa en el desarrollo de aptitud clínica en Geriatría. Inv Ed Med 4: 155-160.

22. Armenta G, Díaz Z, Valencia J, et al. (2015) Manejo de la obesidad en el primer nivel de atención con un programa intensivo de cambio de estilo de vida. Nutr Hosp 32: 1526-1534.

23. María José Luque Hernández, Francisca Leiva Fernández, Sonia Palma Rodríguez, et al. (2008) Eficacia de una intervención 
terapéutica sobre el exceso de peso en atención primaria. Aten Primaria 40: 407-412.

24. Moñino M (2014) Desigualdad: ¿condenados a ser obesos? Rev Esp Nutr Hum Diet 18: 56-57.

25. Crystell Guadalupe Guzmán-Priego, Guadalupe del C BaezaFlores, Daniel Atilano-Jiménez, et al. (2017) Efecto de una intervención educativa sobre los parámetros bioquímicos de pacientes diabéticos de un servicio médico institucional. Aten Fam 24: 82-86.

26. Alamo P, Poyato F (2018) Mantenimiento a largo plazo de la pérdida de peso o de la estabilidad ponderal en individuos obesos: Análisis longitudinal retrospectivo de una población real. BMI Journal Seco 8: 2277-2281.

27. Arrebola V, Gómez C, Fernández F, et al. (2013) Eficacia de un programa para el tratamiento del sobrepeso y la obesidad no mórbida en atención primaria y su influencia en la modificación de estilos de vida. Nutr Hosp 28: 137-141.

28. Álvarez C, Ramírez R, Flores M, et al. (2012) Efectos del ejercicio físico de alta intensidad y sobrecarga en parámetros de salud metabólica en mujeres sedentarias, pre-diabéticas con sobrepeso u obesidad. Rev Med Chile 140: 1289-1296.

DOI: $10.36959 / 577 / 483$

Copyright: (C) 2018 Karina JH, et al. This is an open-access article distributed under the terms of the Creative Commons Attribution License, which permits unrestricted use, distribution, and reproduction in any medium, provided the original author and source are credited. 